\title{
Contrapontos da estética machadiana com o romantismo brasileiro a partir da leitura de $A$ mão e a luva
}

\author{
Raquel Alves Mota $^{1}$
}

RESUMO: Discute-se como A mão e a luva prossegue uma forma literária já delineada no romance anterior de Machado de Assis. A relação do escritor com o Romantismo brasileiro é trazida a debate no sentido de visualizar os contrapontos com a nova estética à qual Machado se filia.

ABSTRACT: It is been discussed how "A Mão e a Luva" goes on with a literary form already outlined in the previous novel by Machado de Assis. The relation between this author and Brazilian Romanticism is brought up in order to elicit the counterpoints of the new aesthetics to which Machado de Assis is consorted with.

PALAVRAS-CHAVE: Romantismo; Estética; Forma.

KEYWORDS: Romanticism; Aesthetics; Form.

O período em que Machado de Assis publica seus quatro primeiros romances pertence à cronologia do Romantismo brasileiro. Designado por alguns como a fase romântica machadiana, o certo é que, por meio de um olhar mais arguto, pode-se inviabilizar essa conceituação. O foco da análise será A mão e a luva, segundo romance de Machado, publicado em 1874. Conjugando a leitura do romance com o pensamento crítico machadiano e com a fortuna crítica que sobre o romance repousou, procura-se mostrar a incoerência de $A$ mão e a luva ser alocado como pertencente à escola romântica. Ao contrário do que indicaria, a rigor, essa alocação, percebe-se, nesse segundo romance, a insistência - visto que esse projeto se inicia com Ressurreição em mostrar como a estética romântica já se encontrava anacrônica. Visando alcançar esse objetivo, repassam-se algumas características do Romantismo tal como se apresentou no Brasil e, posteriormente, discute-se como essa chamada "primeira fase machadiana" (MACHADO, 1975, p. 57) se distancia da estrutura tipicamente romântica comum na literatura brasileira.

Primeiramente é preciso abrir parêntese, no escopo de se delinear os contornos do Romantismo do qual Machado se distancia. No artigo de Nunes (1993), o autor defende que o romantismo deve ser estudado considerando-se suas duas perspectivas: a

\footnotetext{
${ }^{1}$ Raquel Alves Mota faz parte do corpo discente do Pós-Lit (UFMG), no qual realiza seu doutoramento em Teoria da Literatura e Literatura Comparada. O presente trabalho foi realizado no período de curso das matérias do mestrado, quando a pesquisa se centrava sobre Machado de Assis: dissertação defendida em fevereiro de 2011.
} 
psicológica e a histórica. A perspectiva histórica está na localização datada desse movimento, ou seja, como um período, oscilante, que se estende do final do século XVIII aos fins da primeira metade do século XIX. Por outro lado, quando se discute a vertente psicológica desse movimento, percebe-se que o Romantismo se caracteriza pela "ascendência da forma conflitiva de sensibilidade enquanto comportamento espiritual definido" (NUNES, 1993, p. 52). Essa postura se consolida em decorrência de uma "configuração do mundo relativa a um período de transição", como aponta Nunes, como uma forma de distanciamento das crises pelas quais atravessava a Europa. O Romantismo tem como uma das suas características centrais a oposição ao pensamento Iluminista, ao mesmo tempo em que se aproxima dos matizes filosóficos do Idealismo, como da "metafísica do Espírito de Fichte e da metafísica da Natureza de Schelling" (NUNES, 1993, p. 52). Retornando às duas perspectivas do romantismo, Nunes afirma que as características psicológicas desse movimento ultrapassam o advento da Modernidade ou a cronologia do próprio Romantismo.

O Romantismo brasileiro se vincula, de forma mais marcante, ao PréRomantismo alemão (o Sturm und Drang) e à manifestação pós-romântica alemã (o Biedermeier) do que a uma "atitude de reflexão mais prudente dos românticos alemães" (VOLOBUEF, 1999, p. 399). O Romantismo eclode na Inglaterra do séc. XVIII, chegando a diversas partes da Europa, sendo que a Alemanha tem sua parcela de primazia no movimento, dada a influência de seu pensamento pelo mundo. A importância do Romantismo alemão está, principalmente no seu primeiro momento, nas figuras de Goethe e Schiller, que dão o tom ao Sturm und Drang, que influenciará o Romantismo francês, vertente que chega ao Brasil. O Pré-Romantismo alemão tem exponencial participação no pensamento romântico, não somente dos brasileiros, mas do conjunto dos povos latinos (VOLOBUEF, 1999, p. 405). Quando jovens, Goethe e Schiller, representantes da nova estética, encabeçam o movimento, por meio de manifestos, e de emblemáticas obras literárias, como o Werther, de Goethe, por exemplo. Segundo Volobuef (1999), em seu trabalho de cotejo do Romantismo alemão e do brasileiro, Werther sintetiza as características do Sturm und Drang, porque:

[e]m Werther encontra-se como que uma síntese do Sturm und Drang: o artista imaginativo e solitário (gênio); atração pelo ermo e pela Natureza; expansão incontida do sujeito num sentimentalismo sem fronteiras; amor impossível; morte trágica e loucura; repúdio ao racionalismo, às leis e à ordem; frêmito de rebeldia contra a sociedade materialista (...). (VOLOBUEF, 1999, p. 402) 
O Romantismo brasileiro, como é apontado, posteriormente, por Volobuef (1999), segue diretrizes estabelecidas pelo romance de Goethe, como, por exemplo: o “acentuado sentimentalismo" e o "grande apreço pela natureza". Propõe-se, então, aqui, seguir mais de perto essas diretrizes ou como o Romantismo brasileiro apropria-se de “conceitos" do Pré-Romantismo alemão.

Alfredo Bosi (1993), em Imagens do Romantismo no Brasil, sublinha como a paisagem descrita nos romances influi no estado de alma da personagem: "[a] metáfora romântica mais simples é sempre a que se funda sobre alguma correlação entre paisagem e estado de alma" (BOSI, 1993, p. 245). Para exemplificar sua assertiva, Bosi procura redesenhar o quadro presente no romance alencariano, a partir de O Guarani. Segundo Bosi, o "castelo" dos Mariz, alocado no meio da selva brasileira, busca estabelecer vínculos entre o selvagem e o conquistador. As contradições que querem ser suplantadas no projeto desse edifício, porém, se evidenciam nas "rachaduras", que antecipam o futuro desastre. A construção dos Mariz, bem como toda a arquitetura do projeto, filiado à natureza brasileira, exemplifica os sentimentos que envolvem os dois povos ali tratados: o índio e o português. Cada utensílio ali disposto representa um desses povos, na tentativa de fundi-los em apenas um. Bosi sublinha, a partir de sua análise, a especificidade da natureza no Romantismo brasileiro, que tem por função mostrar a peculiaridade do nacional, tendo o exotismo como elemento de valorização da pátria.

Bosi também pontua a importância do subjetivismo romântico como característica central que o diferencia das estéticas anteriores. Deixando de lado a clareza, busca-se pintar os costumes por meio de um sentimentalismo marcado pelo “subjetivismo e pela ironia" (BOSI, 1993, p. 245). A partir disso, a irresolução e ambivalência perpassam o conflito romântico. As personagens são marcadas por sentimentos díspares, mas que não se projetam externamente; ou seja, a personagem apresenta-se com uma disposição, em dado momento da história, e sem mais esclarecimentos, há uma mudança de postura, que leva ao fim o conflito. Nele, não se desenvolvem, porém, os motivos que conduzem as personagens a abandonar uma opinião. O esquema básico do romance romântico pode ser assim sintetizado: 
de re-harmonização, recompondo-se como narrativa de ilusões (ainda que melancolicamente refeita pelas utopias do amor idealizado e da morte). (BOECHAT, 2003, p. 131)

Machado dialoga com a estética romântica, em sua produção crítica. No emblemático "Instinto de nacionalidade" (1873), percebe-se o rechaço de uma poética nos moldes do romantismo brasileiro. A estética que aqui vigorava foi assim caracterizada, pelo romancista: "[o] romance brasileiro recomenda-se especialmente pelos toques do sentimento, quadros da natureza e de costumes, e certa viveza de estilo mui adequada ao espírito do nosso povo" (MACHADO, 1994, p. 805). Buscando outros "ares", Machado ansiava por um romance em que se fizesse mostrar o conturbado encontro do homem consigo mesmo, em que se analisariam os conflitos ali gerados. Assim, o foco da crítica está, em certa medida, em combater esse chamado "instinto de nacionalidade", aclamado em um universo romântico, ou essa relação do indivíduo com a pátria, o que, por sua vez, abre margem ao exotismo, na sua representação no romance; ou seja: o tão aclamado pela crítica romântica, a busca pela peculiaridade brasileira, o que garantiria sua independência frente às outras literaturas, principalmente à portuguesa, esse exotismo é severamente condenado por Machado.

Buscando desafiar a estética romântica que ainda predominava, Machado lança, em 1872, seu primeiro romance - Ressurreição - que, de certa forma, adiantava aquilo que é discutido em "Instinto de nacionalidade" (1873). Aqui, enfoca-se somente o prefácio de Ressurreição, no qual já se observa registro do plano que Machado procura desenvolver na obra: “[n]ão quis fazer romance de costumes; tentei o esboço de uma situação e o contraste de dois caracteres; com esses simples elementos busquei o interesse do livro" (MACHADO, 2007, p.14). Deixando a plataforma de uma estética romântica (a "luta das paixões", a "pintura dos costumes" e os "quadros da natureza"), Machado procura ir além, buscando tratar, especificamente, o homem em conflito, desenvolvendo personagens que frustram as expectativas nelas depositadas, na medida em que a sua perspectiva encontra-se sempre aberta. $\mathrm{O}$ contraste de um duplo querer ou as razões inconciliáveis que se atritam são os objetos que promovem a trama. Como exemplo, tem-se o protagonista do primeiro romance machadiano que, visceralmente, ironiza os comportamentos românticos de tal forma que, ao final da história, não consegue se harmonizar com um desfecho tipicamente romântico.

Antonio Candido (1995), propondo o "Esquema de Machado de Assis", dialoga com essa confluência de disparidades presente no texto machadiano. As ações mais 
descabidas são celebradas como se fossem coisas bem naturais. Deixando a "falsa moral" de lado, pois não se pode confundir "a arte com a moral" (MACHADO, 1994, p. 913), Machado muda as ordens das coisas, com o consentimento de seu leitor, apoiado pelas artimanhas do seu cada vez mais ousado narrador.

Em Machado, o narrador se compraz na mobilidade pura, assumindo todo gênero de caracteres, desempenhando os papéis mais diversos, articulando uma alternância sistemática de perspectivas, modulando vários pontos de vista, sempre recusando a possibilidade de se imobilizar na representação doutrinária de um só papel, na adoção monológica de um ponto de vista pretensamente normativo.

(SOUZA, 1998, p. 65)

O narrador machadiano desencadeia o embate entre os muitos dizeres - ou quereres das personagens. Cria-se um palco em que pelejam o homem com suas ideias: estas, muitas vezes, em desacordo com o corriqueiramente respeitável. Souza (1998) classifica essa atuação do narrador como criadora do estilo machadiano, caracterizado pelo "multiperspectivismo". Abandonando a personagem tipo, uno sobre si mesmo, Machado reclama a abordagem das interfaces do homem, da representação dos seus mais íntimos sentimentos. Um narrador capaz de se aproximar das múltiplas inclinações que seduzem o comportamento da personagem. A dialética das personagens machadianas advém da negativa à permanência no meramente externo, na chamada “pintura de costumes”. Isso, porém, não quer dizer que todas as personagens recebem o mesmo tratamento. Há desde o "indivíduo" - o apenas mencionado, bem como o "tipo", representado por um só dizer, chegando à personagem "pessoa" (BOSI, 2006, p. 158), quando se lhe permite a abordagem de confluências de suas vontades: este caracteriza o alvo na estética machadiana.

Para Seixas Guimarães (GUIMARÃES, 2004, p. 138), o grande propósito do narrador de $A$ mão e a luva é angariar a confiança do leitor. Firma-se um acordo entre essas duas instâncias, para que o leitor não rejeite as mais íntimas resoluções da protagonista, Guiomar. É de suma importância uma conciliação, para que não se impeça a denúncia do anacronismo dos clichês românticos. Esse "tom conciliatório", promovido pelo narrador, seria a grande diferença com o primeiro romance de Machado. Em Ressurreição, o narrador busca, reiteradamente, frustrar as expectativas do leitor já acostumado às prerrogativas de uma narrativa romântica. É como se Machado quisesse acentuar uma quebra com os padrões da estética romântica. Reiterase, sempre, esse mesmo dizer, na busca de se convencer o leitor da mudança de visão de 
mundo, por meio da própria contestação dos paradigmas antigos. Ambas as obras já desafiam o romantismo, mediante uma relação dialética com o movimento. A desconstrução ocorre de dentro, priorizando um debate com o leitor, advertindo-o da necessidade de uma ruptura com as já antigas convenções. Dessa forma, torna-se difícil sustentar o discurso de uma fase romântica machadiana, dado que, a todo o momento vê-se a negativa das bases desse pensamento, por meio de uma leitura de seus clichês, a contrapelo.

O prólogo do romance A mão e a luva mostra que Machado permanece fiel ao seu projeto literário, iniciado com Ressurreição (1872) e defendido criticamente em "Instinto de nacionalidade" (1873).

Convém dizer que o desenho de tais caracteres, — o de Guiomar, sobretudo, - foi o meu objeto principal, senão exclusivo, servindome a ação apenas de tela em que lancei os contornos dos perfis. Incompletos embora, terão eles saído naturais e verdadeiros? (MACHADO, 2009, p. 49)

Machado não se abstém de insistir no trabalho com os caracteres de seus personagens. Guiomar é, aqui, o foco da análise como protagonista que ganha estatuto de pessoa, sacudida pelas reações de sua vontade. A provável herdeira da fortuna da baronesa queria consolidar sua ascensão social com um casamento promissor. A protagonista avalia os três pretendentes, contrabalanceando as perdas e ganhos das possíveis escolhas. Ciente das dificuldades vividas na infância, Guiomar não queria abrir mão da virada triunfal, que a exporia, com destaque, aos olhos da sociedade. Essa personagem revela muito da concepção que Machado preconizava para a constituição de personagens. Ela não apresenta um olhar único em relação à vida. Ao contrário, seus conflitos internos se esclarecem, mostrando um jogo de perspectivas e, assim, uma formação conflituosa do seu caráter, e dos sentimentos que a envolvem, conforme se percebe neste trecho, por exemplo:

Mrs. Oswald abanou a cabeça e saiu; Guiomar acompanhou-a com os olhos, a sorrir, satisfeita de si mesma, e a murmurar tão baixo que mal a ouvia o seu próprio coração:

- Sonhos, não, realidade pura. (MACHADO, 2009, p. 85)

Guiomar, após a declaração de amor feita por Estevão, sente o conflito de sentimentos, em decorrência do embate entre aquilo que ela queria para si e aquilo de que os chamados sonhos poderiam privá-la. Depois que Mrs. Oswald declara que a vida 
era realidade e não sonhos, ela recupera o controle de seus sentimentos, por meio da razão. O narrador desse romance apresenta os fatos de maneira pormenorizada, porque não quer que o leitor perca o raciocínio que se desenvolve na trama. Exemplo desse esmero está, por exemplo, no excerto transcrito a seguir:

(...) viu repentinamente aparecer-lhe diante, a cinco ou seis passos do lugar em que estava, um rancho de moças, todas bonitas, que arrastavam por entre as árvores os seus vestidos, e faziam luzir aos últimos raios do sol poente as jóias que as enfeitavam (...) mas foramse, e com elas os olhos da interessante pequena, que ali ficou largo tempo absorta, alheia de si, vendo ainda na memória o quadro que passara. (MACHADO, 2009, p. 75)

O trecho anterior mostra o episódio em que Guiomar, quando criança, vê suas vizinhas ricas se divertindo, o que, automaticamente, a conduz a uma profunda tristeza. Percebese que Guiomar faz a comparação da vida que tinha com sua mãe, em precárias condições, com a daquelas moças. Esse raciocínio, após a leitura do trecho acima, apresenta-se de fácil entendimento; porém, o narrador, segundo Guimarães (2004, p. 140), não querendo que o leitor o perca, retorna a ele quando Guiomar, já adulta, sacramenta a decisão da impossibilidade de amar o romântico Estevão. In verbis:

Criança, iam-lhe os olhos com as sedas e as jóias das mulheres que via na chácara contígua ao pobre quintal de sua mãe; moça, iam-lhe do mesmo modo com o espetáculo brilhante das grandezas sociais. Ela queria um homem que, ao pé de um coração juvenil e capaz de amar, sentisse dentro em si a força bastante para subi-la aonde a vissem todos os olhos. (MACHADO, 2009, p. 121)

O narrador, dessa forma, mostra os dilemas que perpassam a alma de Guiomar; porém, ainda tutela o leitor para não os perder, explicando-os, com o receio que os recursos usados não fiquem bem compreendidos: “(...) só uma vez aceitara a obscuridade e a mediania; foi quando se propôs a seguir o ofício de ensinar; mas é preciso dizer que ela contava com a ternura da baronesa" (MACHADO, 2009, p. 121). Depois da investida de Jorge, sobrinho da baronesa, Guiomar sente a urgência de decidir seu futuro conjugal. Tinha ela rejeitado a proposta de Estevão, dado que este representava um ser meramente sentimental, incapaz de construir o futuro que ela projetava para si. Esse primeiro pretendente não recebe a complacência da moça, nem do narrador, que, em consórcio com suas razões, inviabiliza a comunhão. Para isso, o narrador apresenta Estevão como o antiquado romântico, que se filia a métodos ultrapassados, que não condiz com as pretensões de Guiomar. Estevão carrega os 
estigmas românticos; e estes são levados a xeque, dado o seu confronto com a modernidade, representada por Guiomar e pelo seu futuro escolhido: Luiz Alves.

Com a decisão de Guiomar em favor de Luiz Alves, sucumbe o projeto romântico de Estevão. A também rejeição de Jorge, devido à sua "fraca compleição moral" ou à sua trivialidade, colore o romance de uma dupla investida contra o Romantismo. Primeiro, quando Estevão é descartado, conjuntamente se rejeitam os padrões românticos por ele sustentados. Com a predileção por Luiz Alves, ao invés de Jorge, firma-se "o acordo" de ambições entre o par, mostrando a sisudez do pensamento difundido no romance.

Guiomar é apresentada, pelo narrador, como uma mulher ambiciosa. O seu próprio noivo chega a essa conclusão, motivo pelo qual ele resolve sacramentar a união. O narrador, porém, não querendo defini-la como uma vilã, ou com um caráter uno, e este mau, "fora" do mundo de seu leitor, faz com que este a julgue, por meio das observações que Guiomar faz a Luiz Alves, a respeito de si mesma:

Saiba pois que sou muito senhora da minha vontade, mas pouco amiga de a exprimir; quero que me adivinhem e obedeçam, sou também um pouco altiva, às vezes caprichosa, e por cima de tudo isto tenho um coração exigente. Veja se é possível encontrar tanto defeito junto.

Luiz Alves respondeu que eram tudo qualidades excelentes... (MACHADO, 2009, p. 149)

O narrador, segundo Guimarães (2004, p. 137), dessa forma, conduz a leitor a repensar as atitudes de Guiomar para, assim, chegar às mesmas conclusões que Luiz Alves; ou seja: Guiomar deixa de ser vista apenas pelo seu caráter de mulher — ambiciosa e calculista - , para ser apreciada na condição de uma mulher consciente de seu querer. $\mathrm{O}$ narrador redime a protagonista, mostrando que os mesmos conflitos e atitudes desta estão presentes no mundo de (e no) seu leitor.

Fausto Cunha (1971) argumenta acerca da dificuldade de se classificar a "geração de 70" no Oitocentos. Pode-se atestar, tendo como exemplo as obras machadianas, que a dificuldade não se apresenta somente em se tratando de poesia, objeto do crítico, devido ao fato de que as discussões são intensas, em relação a uma possível classificação dos romances machadianos. Em 1905, em prólogo a uma nova edição de Ressurreição, Machado estabelece a diferença entre os seus primeiros romances e os posteriores, aceitando uma possível primeira fase de sua obra literária. $\mathrm{O}$ próprio Machado de Assis declara a "diferença de composição", quando da comparação 
dos seus primeiros romances com os derradeiros. Parte da crítica percebe nisto um projeto literário, tendo em vista as mudanças que ocorreram na "feição da obra". Aceitando essa hipótese, percebe-se que Machado, trabalhando o pensamento crítico do leitor, trilha esse caminho, com o objetivo de iniciar o leitor nos recursos estéticos que utiliza, para que, nos romances posteriores, o leitor possa, independentemente, compreendê-los, já que essa faculdade será dele requerida para o entendimento de sua ficção. Escreve ele, ipsis litteris:

Os trinta e tantos anos decorridos do aparecimento desta novela a reimpressão que ora se faz parece que explicam as diferenças de composição e de maneira do autor (MACHADO, 2009, p.50).

O trecho acima está na introdução escrita em 1907 parauma nova edição, trinta anos após o lançamento do romance $A$ mão e a luva. Nesse ano, Machado já tinha

publicado os seus outros romances, da chamada segunda fase. Perceptível é o desenvolvimento estético de Machado, em acordo com os seus planos defendidos desde o primeiro romance. Não se deve, porém, perder de vista que o diálogo promovido entre os primeiros romances de Machado e a estética romântica não objetiva um acordo; antes, postula a diferença do projeto ousado que, então, se iniciava.

\section{Referências Bibliográficas}

ASSIS, Machado de. Obra completa. (3 vol.) Rio de Janeiro: Nova Aguilar, 1994. Ressurreição. 2 ed. Porto Alegre, RS : L\&PM, 2007. A mão e a luva. 2 ed. Porto Alegre, RS : L\&PM, 2009.

BAKHTIN, Mikhail. Problemas da poética de Dostoievski.Trad. Paulo Bezerra. Rio de Janeiro: Forense-Universitária: 1981.

BOECHAT, Maria Cecília. Paraísos artificiais: o romantismo de José de Alencar e sua recepção crítica. Belo Horizonte: Editora UFMG/Pós-Lit FALE/UFMG, 2003.

BOSI. Alfredo. "Imagens do Romantismo no Brasil" In: GUINSBURG, J. (org.) $O$ Romantismo. São Paulo: Perspectiva, 1993, p. 239-256.

Uma hipótese sobre a situação de Machado de Assis na Literatura Brasileira. In: Machado de Assis: o enigma do olhar. São Paulo: Companhia das Letras, 2006, p. 151-163.

CANDIDO. Antonio. "Esquema de Machado de Assis" In: Vários Escritos. $3^{\mathrm{a}}$ ed. São Paulo: Duas Cidades, 1970, p. 17-39. 
CUNHA. Fausto. O Romantismo no Brasil: de Castro Alves a Sousândrade. Rio de Janeiro: Paz e Terra, 1971.

GUIMARÃES, Hélio de Seixas. Os leitores de Machado de Assis: o romance machadiano e o público de literatura no século 19. São Paulo: Nankin/Edusp, 2004.

NUNES. Benedito. “A Visão Romântica” In: GUINSBURG, J. (org.). O Romantismo. São Paulo: Perspectiva, 1993, p. 51-74.

SOUZA, Ronaldes de Melo. "O estilo narrativo de Machado de Assis" In: Ronaldes de Melo e Souza; Antônio Carlos Secchin; José Maurício Gomes de Almeida. (org.). Machado de Assis - uma revisão. $1^{a}$ ed. Rio de Janeiro: In-Fólio, 1998, v. 1, p. 6579.

VOLOBUEF, Karin. Frestas e arestas: a prosa de ficção do Romantismo na Alemanha e no Brasil. São Paulo: Fundação Editora da UNESP, 1999. 